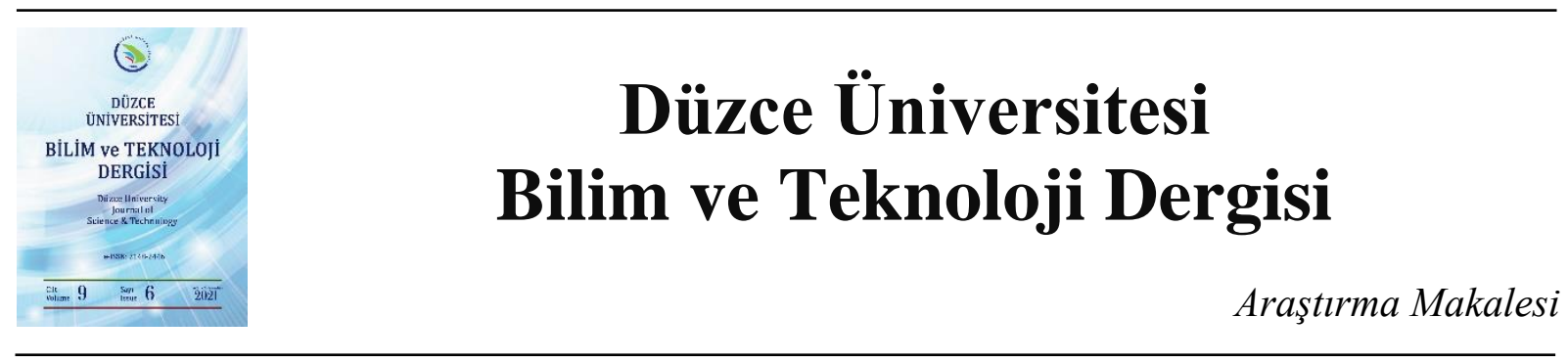

\title{
Akciğer X-Ray Görüntülerinden COVID-19 Tespitinde Hafif ve Geleneksel Evrişimsel Sinir A ̆g Mimarilerinin Karşılaştırılması ${ }^{1}$
}

\author{
Furkan ERYILMAZ $^{\mathrm{a}, *}$, (D) Hacer KARACAN ${ }^{\mathrm{b}}$ \\ ${ }^{a}$ Bilgisayar Bilimleri Bölümü, Bilişim Enstitüsü, Gazi Üniversitesi, Ankara, TÜRKIYE \\ ${ }^{b}$ Bilgisayar Mühendisliği Bölümü, Mühendislik Fakültesi, Gazi Üniversitesi, Ankara, TÜRKIYE \\ * Sorumlu yazarin e-posta adresi: eryilmaz.furkan@gmail.com
}

DOI: 10.29130/dubited.1011829

\begin{abstract}
$\underline{\mathrm{OZZ}}$
Solunum sistemine etki eden ve ileri vakalarda ölüme neden olan korona virüs salgını yaklaşık iki yıldır devam etmektedir. Her ülkenin salgın ile mücadele yöntemi farklı olmasına rağmen ortak izlenen metot ise hastalığın tespiti ve izolasyonudur. Tespit ve izolasyon için en kritik adım ise COVID-19 tanısının doğru ve hızlı konulmasıdır. Akciğer X-Ray görüntülerinde virüse özgü bulgulara rastlanılması, bu verilerin hastalık teşhisinde kullanılabileceğini göstermektedir. İlgili çalışmanın amacı, makine öğrenmesi yöntemleri ile COVID-19 ve diğer akciğer hastalıklarına ait X-Ray görüntülerini işleyerek çoklu sınıflandırma yapmaktır. Bu sayede kriz anında tanı koyma ve izolasyon için yardım alınacak alanında uzman olmayan personele mobil cihazlar vasıtasıyla karar aşamasında destek sağlanması hedeflenmektedir. Bu amaçla: COVID-19, Normal, Akciğer Opasitesi, Diğger Pnömoni etiketlerine ait 11,293 X-Ray görüntüsünden oluşan veri seti MobileNetV2, NASNetMobile, Xception ve DenseNet121 CNN ağları kullanılarak sınıflandırılmış ve sonuçlar karşılaştırılmıştır. En başarılı sonuçlar DenseNet121 ve MobileNet ağları ile elde edilmiş olup sırası ile \%92,16 ve \%91,78 doğruluk oranıyla sınıflandırma gerçekleştirilmiştir.
\end{abstract}

Anahtar Kelimeler: Evrişimsel sinir ă̆ları, Koronavirüs, COVID-19, Transfer öğrenimi, X-Ray

\section{Comparison of Lightweight and Traditional CNN Architectures in COVID-19 Detection from Lung X-Ray Images}

\begin{abstract}
The corona virus epidemic, which affects the respiratory system and causes death in advanced cases, has been going on for about two years Although each country's method of fighting the epidemic is different, the common and valid method is the detection and isolation of the disease. The most critical step for detection and isolation is the correct and fast diagnosis of COVID-19. Virus-specific findings in lung X-ray images shows that these data can be used in the diagnosis of the disease. The aim of the related study is to multi classify by processing X-Ray images of COVID-19 and other lung diseases with machine learning methods. In this way, it is aimed to provide support to the personnel who are not experts in their fields, who will be helped for diagnosis and isolation during the crisis, at the decision stage through mobile devices. For this purpose: The data set consisting of 11,293 XRay images of COVID-19, Normal, Lung Opacity, Other Pneumonia labels was classified using the MobileNetV2, NASNetMobile, Xception and DenseNet121 CNN networks and the results were compared. The most successful results were obtained with DenseNet121 and MobileNet networks, and classification was performed with $92.16 \%$ and $91.78 \%$ accuracy rates, respectively.
\end{abstract}

Keywords: Convolutional neural network, Coronavirus, Transfer learning, X-Ray

${ }^{1}$ ICAIAME 2021 konferansında sunulmuş ve özet metin e-book olarak yayımlanmıştır.

Geliş: 19/10/2021, Düzeltme: 18/11/2021, Kabul: 21/11/2021 


\section{GIRIS}

2019 y1lında Dünya Sağlık Örgütü’ne pnömoni semptomları gösteren yeni bir virüsün varlığ1 bildirilmiştir [1]. Çinli uzmanlar tarafından yapılan ve kaynağı belli olmayan bu virüse ait ilk vakalar Çin'in Wuhan kentinde görülmüştür [1]-[2]. Tüm dünyayı etkisi altına alan bu virüs Dünya Sağlık Örgütü tarafından salgın olarak kabul edilmiş ve ağır akut solunum sendromu-koronavirüs-2 (SARSCov-2) şeklinde adlandırılmıştır [3]-[4]. Koronavirüs ailesinde SARS-COV(Severe Acute Respiratory Syndrome Coronavirus), MERS(Middle East Respiratory Syndrome Coronavirus) ve SARS-Cov-2 virüsleri insanların solunum sistemine saldırmakta ve ileri vakalarda ölüme yol açmaktadır [3],[5]. Hapşırık ya da öksürük kaynaklı su damlacıkları ve fiziksel temas ile bulaşan bu virüse ait belirtiler; solunum zorluğu, halsizlik, kas ve eklem ağrısı, ateş, koku ve tat kaybı şeklindedir [6]-[7].

Bulaş artış oranın kontrolden çıkması ile beraber DSÖ Mart 2020 tarihinde SARS-CoV-2 virüsünün salgın olarak kabul edildiğini deklare etmiştir. Salgına karşı tüm ülkeler hazırlıksız yakalanmış ve sınırlı sayıdaki hastane, ekipman ve doktor sayısı talebi karşılayamamış olup sağlık alt yapıları çökmüştür. Dünya Sağlık Örgütü verilerine göre şu ana kadar 215 milyon insan hastalanmış ve 4,48 milyon insan hayatını kaybetmiştir [8].

Salgının ilerleyen günlerinde pasif ve mRna tabanlı aşılar geliştirilmesine karşın virüsün farklı varyantlarının çıkması, olası yan etkileri, virüse karşı etkinliği, kaç doz kullanılacağı ülkeler arası paylaşım, lojistik ve aşı karşıtlığı gibi tartışmalar kamuoylarında tartışılmaktadır. Tüm ülkelerin korona virüs salgınında farklı yöntemler izlemesine rağmen geçerli ve ortak kabul tek yaklaşım hastalık tespiti ve izolasyondur. Bu nedenle hastalık tespitinin doğru yapılması kritik öneme sahiptir.

COVID-19 teşhisinde altın standart kabul edilen PCR testi, DPI testi, salya testi, antikor testi, akciğer doku biyopsisi ve tıbbi görüntüleme yöntemleri kullanılmaktadır [76]. En sık kullanılan yöntemler; RT-PCR, bilgisayarlı tomografi ve akciğer x-ray görüntüleridir. RT-PCR testlerinin bir saatten birkaç güne sonuç verme süresinin olması, yanlış sonuç yatkınlığı, manuel işlem gerektirmesi ve kitteki antijen miktarı ile sonuçların bağımlılığı gibi dezavantajları söz konusudur [8],[9],[10].

DSÖ'nün Ekim 2020'de ülkelere yaptığı tavsiyede tıbbi görüntüleme yöntemlerinin korona virüs teşhisi ve tedavi süresi içinde hasta takibinde kullanılması uygulanabilir etkili bir yöntem olarak kabul edilmiştir [11]. Bilgisayarlı tomografi, yüksek kalitede görüntüler üretmesine karşın yüksek radyasyon temelli çalışması, hamile ve çocuklar için uygulanabilir olmaması, görüntü üretme süresinin uzun ve yüksek maliyetli olması, BT odasının bulaş riskini artırması nedeniyle artık tercih edilmemektedir [12]. Bu yöntem daha çok vaka durum takibinde daha verimli bulunmaktadır [13].

X-Ray görüntüleme yöntemi 15-20 dakikada sonuç veren, kolay erişilebilir, düşük radyasyonlu, 2B görüntü üreten ve çoğu sağlık merkezinde standart donanım olarak kabul edilen yaklaşımdır [10],[12]. PCR testi negatif çıkan hastaların \%9'unda göğüs X-Ray görüntülerinde bu bulgular tespit edilmiştir [20]. Tüm bu avantajlara rağmen X-Ray görüntülerinin göz yordamı ile analiz edilmesi ancak uzman radyologlar tarafindan 5-6 dakikalık çalışma ile yapılabilmektedir [12],[14]. COVID-10 bulgular ile diğer pnömonilerin benzerlik göstermesi doğru tanı koyma sürecini zorlaştırmaktadır. Karşılaşılan bu kısıtların tamamının makine öğrenmesi ve görüntü işleme yöntemleri ile aşılması mümkün gözükmektedir. Geliştirilen yöntemlerin mobil cihazlara uygulanabilir hale getirilmesi ise doktorlar üzerinde yükü önemli ölçüde azaltacaktır. Destek personellerinden tanı koyma sürecinde de istifade edilecektir.

Karthik ve arkadaşları [6], sınıflandırma ve enfekte bölgelerin tespitine çalışmışlardır. Özellik çıkarımında kullanılan filtrelerde derin öğrenme uygulayarak daha iyi performanslar hedeflenmiştir. Akı1lı filtrenin sinıflandırma etiketine olan tepkisi optimizasyon algoritmasına girdi olarak verilmektedir. Model performansı \%92,42 doğruluk oranı olarak belirlenmiştir. Monshi ve arkadaşları [7], EfficentNet-50 temelli CovidXRayNet adını verdikleri çözümlerinde performans artımına odaklanmışlardır. $\mathrm{Bu}$ amaçla hiper parametreler ve veri artırım yöntemlerini detaylı incelenmiştir. En 
başarılı hiper parametreler; 32 boyutlu veri paketi, 30 döngü sayısı olup veri artımında ise 20 derece döndürme, 0,2 oranında yeniden şekillendirme, 0,3 oranında parlaklık değişimi, 1,2 değerinde yakınlaştırma ve normalizasyon olarak belirlenmiştir. Veri üzerinde COVID-19, Normal, diğer pnömoni etiketlerine göre yapılan sinıflandırmalarda sırası ile VGG-19 ve ResNet modellerinde $\% 11,93, \% 4,97$ oranında başarı artırımı sağlamıştır. CovidXRayNet modeli ise \%95,82 doğruluk oranında sınıflandırma yapmıştır. COVID-Net isimli çalışmaları ile Lin ve arkadaşları [9] X-Ray görüntülerini kullanarak normal, bakteriyel ya da viral pnömoni ve COVID-19 etiketlerine göre sınıflandırma yapmışlardır. Veri seti dağılımı 8,066 sağlıklı, 183 COVID-19 ve 5,538 diğer pnömoni şeklinde olup toplam 13,800 görüntü bulunmaktadır. Çalışmada yüksek performans ve kolay eğitilebilirlik için kalıntı ağ yapıları tercih edilmiştir. Sonuçlar COVID-Net ağının \%92,6 doğruluk oranında sınıflandırma yaptığını göstermiştir.

Alan ve arkadaşları [11] yaptıkları çalışmada görüntüden özellik çıkarımı adımına yoğunlaşmışlardır. Daha iyi özellik haritaları için histogram (HOG) ve evrişimsel sinir ă̆ temelli iki yöntem kullanılmıştır. Verideki gürültüler MADF yaklaşımı ile elimine edilmiştir. İşlemler verinin gri ve tonlarına çevrilmesi ile başlamakta ve hedef bölgelerin seçilip kalan kısımların atılmasını kapsamaktadır. Kalan bölgeler üzerine önerilen özellik çıkarım yaklaşımları uygulandıktan sonra çıktılar sınıflandırma için modele verilmiştir. VGGNet ağı kullanılarak 1,979 COVID-19, 3.111 negatif görüntü sınıflandırılmıştır. Modelin başarı oranı \%98,36 olarak belirlenmiştir. Wang ve arkadaşları [12] derin öğrenme yöntemlerini kullanarak hem COVID-19 hem de nüfuz etmiş akciğer dokularının tespitine çalışmışlardır. Veri seti büyüklüğü 3,583 görüntü olup sınıflandırma adımında ResNet modeli kullanılmıştır. Pozitif sınıflandırılan görüntülerdeki lokalizasyon sağ, sol ve hangi bölgede olduğunun tespiti yapılmıştır. Değerlendirme bu işlemlerin uzman radyologlar tarafindan da el yordamı ile yapılıp karşılaştırılmasına dayanmaktadır. Sınıflandırma \%98,72, lokalizasyon \%94,62 doğruluk oranında gerçekleştirilmiştir.

CNN modelleri ile korona virüs sınıflandırması yapan Horry ve arkadaşları [13] röntgen, ultrason ve BT görüntülerini kullanmışladır. Transfer öğrenimi temelli VGG16-VGG19, ResNet50, InceptionV3, InceptionResNet, NasNetLarge, DenseNet ağları veri üzerinde denenmiştir. Gürültüyü elimine etmek için N-CLAHE yöntemi uygulanmıştır. VGG19 modelinde en iyi sonuçlar elde edilmiş olup X-Ray, ultrason ve BT görüntüleri için sırası ile $\% 86, \% 100, \% 84$ doğruluk oranları ile sinıflandırma yapılmıştır. DarkNet-19 mimarisini baz alarak DarkCovidNet modelini geliştiren Öztürk ve arkadaşları [15] ikili ve çoklu sınıflandırma yapmıştır. Ham görüntüler üzerinde çalışılmış olup özellik çıkarımı yapılmamıştır. Değerlendirmeler sonucunda ikili ve çoklu sınıflandırmada sırası ile \%98.08 ve \%87.02 doğruluk oranı elde edilmiştir. Karakanis ve Leonridis [16] hafif mimariler üzerine çalışma yapmışlardır. Veri setini büyütmek için çekişmeli üretici ağ yardımı ile sentetik veriler üretilmiştir. Araştırma kapsamında ikili ve çoklu sınıflandırma yapılmışır. Önerdikleri modelin sonuçları ResNet8 ağ1 ile karşılaştırılmıştır. ResNet8 ağında transfer öğrenimi kullanılmasına rağmen önerilen ağda performans1 daha net görebilmek için bu yöntem kullanılmamıştır. Ortaya konan yöntem ikili sınıflandırmada \%99,7, çoklu sınıflandırmada \%98,3 doğruluk oranıyla ResNet8 ağından daha iyi performans sergilemiştir.

Akciğer X-Ray görüntüleri COVID-19 teşhisinde ciddi bir potansiyel taşımaktadır. Makine öğrenmesi yöntemleri ile insan faktörünün elimine edilmesi sahada sağlık çalışanlarının yükünü hafifletecektir. Ayrıca mobil cihazlar için bu yöntemin uygulanabilir hale getirilmesi; tecrübesiz hekimlerin, ikinci basamak sağl1k personellerinin ve çok acil durumlarda asker ve polisin tanı koyma sürecinde görev almasını mümkün kılacaktır. Bu amaçla literatürde yer alan ve başarılı bulunan MobileNetV2, NASNetMobile, Xception ve DenseNet121 evrişimsel ağları (ESA) incelenmiştir. Model seçiminde literatür çalışmaları dikkate alınmış ve bu alanda daha az çalışılan ESA mimarileri seçilmiştir.

Aşağıdaki hedefler kapsamında bu modeller karşılaştırılmıştır.

- Test sürecinde insan faktörünün minimize edilmesi

- Daha hızlı ve doğru tanı koyma

- Gelişmiş ülkelerin test alt yapısın güçlendirme 
- Gelişmemiş ülkelerde ise mevcut kabiliyetleri kullanarak test imkânı sunulması

- Mobil cihazlarda bu yöntemlerin uygulanabilirliğinin değerlendirilmesi

Makale düzeni şu şekilde belirlenmiştir; 1. bölüm giriş, 2. bölüm teknik arka plan, 3.bölüm materyal ve metot, 4 . Bölüm ise sonuç ve tartışma.

\section{TEKNIKK ARKA PLAN}

İlgili çalışma kapsamında X-Ray görüntülerinden evrişimsel sinir ağları vasıtasıyla COVID-19 tespiti yapılmıştır. Tüm modellerde eğitime sıfırdan başlamak yerine başlangıç ağırlıkları transfer öğrenimi yaklaşımı ile ImageNet veri setinden aktarılmıştır.

\section{A. EVRIŞiMSEL SINIIR AĞLARI}

Evrişimsel sinir ağları, görüntüleri analiz ederek veri üzerindeki örüntüyü tespit eden yapay sinir ağ modelleridir [17]. Sinıflandırma için gereken özellikler veri üzerinde matris filtreler uygulanarak çıkarılmaktadır [18]. Diğer derin sinir ağ temelli yöntemlerin aksine görüntü işlemede yüksek performans sergileyen ESA modellerinin karmaşıklığ 1 yönetilebilir düzeydedir [19]. Evrişimsel sinir ağ mimarisi aşağıdaki katmanlardan oluşmaktadır.

- Evrişim Katmanı: Görüntünün ilk işleme alındığı ve özelik çıkarımının yapıldı̆̆ı katmandır. Uygulanan filtreler sonuncunda bu katmanın çıktısı olan özellik haritaları elde edilmektedir [2][8],[20]. Tüm ESA modelinin hesaplama yükünün büyük kısmı burada meydana gelmektedir [19]. Tüm modelin performansı doğrudan çıkarılan özelliğin niteliğine bağlı olup bu katmanda yapılacak olası iyileştirmeler tüm modelin karmaşıklığında düşüş sağlamaktadır.

- Ortaklama Katmanı: Evrişim katmanının çıktısı olan özellik haritalarında uygulanan stokastik, maksimum, ortalama ve boyutsal piramit ortaklama gibi yöntemler yardımıyla minimum düzeyde bilgi kaybı ile boyutlar düşürülmektedir [19]. Yani modelin sınıflandırma için ihtiyaç duyduğu en önemli bilgiler süzülerek hem aşırı öğrenmeye karşı direnç hem de karmaşıklıkta iyileştirmeler elde edilmektedir [21].

- Tam Bağlantılı Katman: Görüntü üzerindeki özellikler ile sınıflandırma etiketleri arasındaki ilişkinin kurulduğu katmandır [20]. Bu katmanlar arasındaki nöronlar birbirlerine tamamen bağlıdır [19].

\section{A. 1. ESA Modelleri}

\section{A.1.1. MobileNetV2}

MobileNetV2 ağları mobil, IOT ya da düşük donanımsal özelliklere sahip cihazlar için geliştirilmiştir. $\mathrm{Bu}$ ağlar sınıflandırma performansını korurken parametre sayısı ve işlem karmaşıklığında önemli ölçüde iyileştirme sunmaktadır [2]-[8],[22]. Mimarisinin doğrusal darboğaz (Linear Bottleneck) ve tersine çevrilmiş kalan (Inverted Residuals) bloklardan oluşması bellek ihyacının düşürülmesine önemli katkılarda bulunmuştur [23]. Evrişim katmanı derinlemesine erişim ve noktasal erişim katmanlarından oluşmaktadır [22]. 


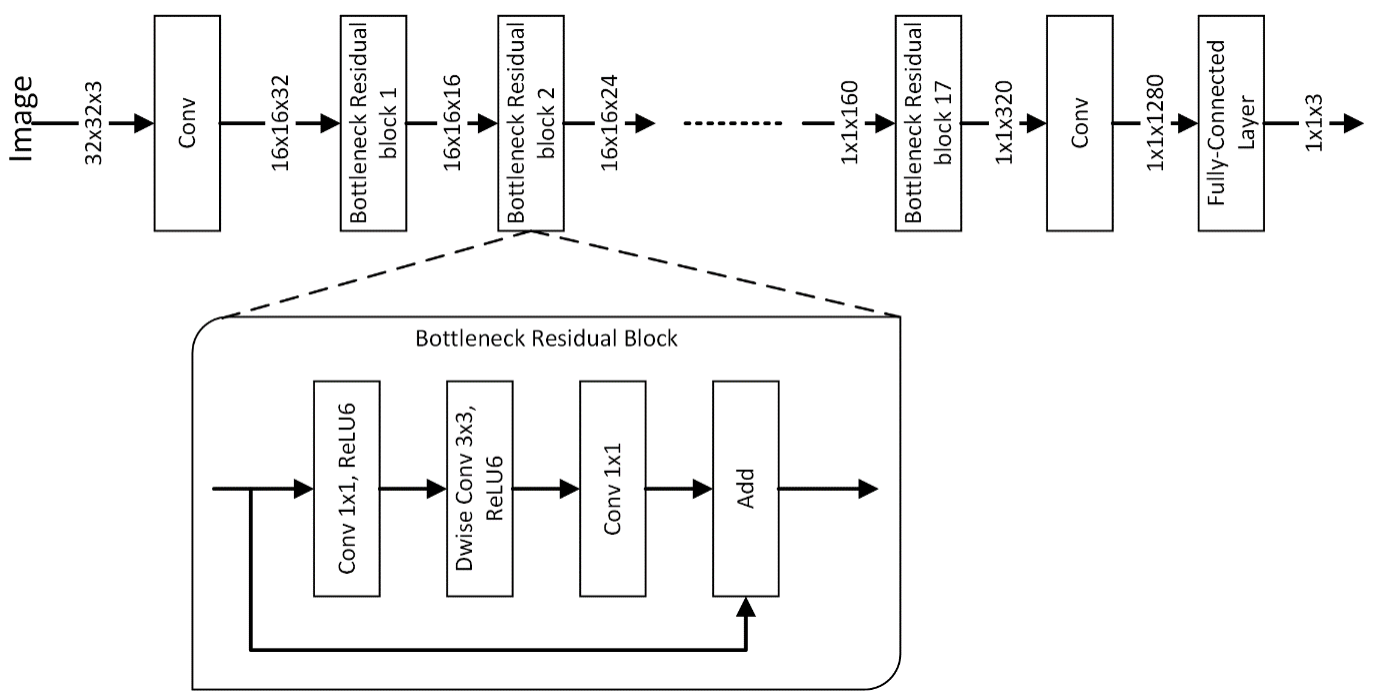

Şekil 1. MobileNetV2 mimarisi [24]

\section{A.1.2. NASNetMobile}

NASNet ağları ölçeklenebilir ESA mimari olup pekiştirmeli öğrenme yöntemi ile iyileştirilmiş ayrılabilir evrişim ve ortaklama gibi basit bloklardan oluşmaktadır. NASNet temelli mimariler ağ kapasitesine göre bu blokların tekrarlanması ile oluşturulmaktadır [2]-[8],[25]. NASNetMobile 5,4 milyon kapasitesi 564 milyon çarpma kapasiteli 12 hücreden oluşmaktadır [26].

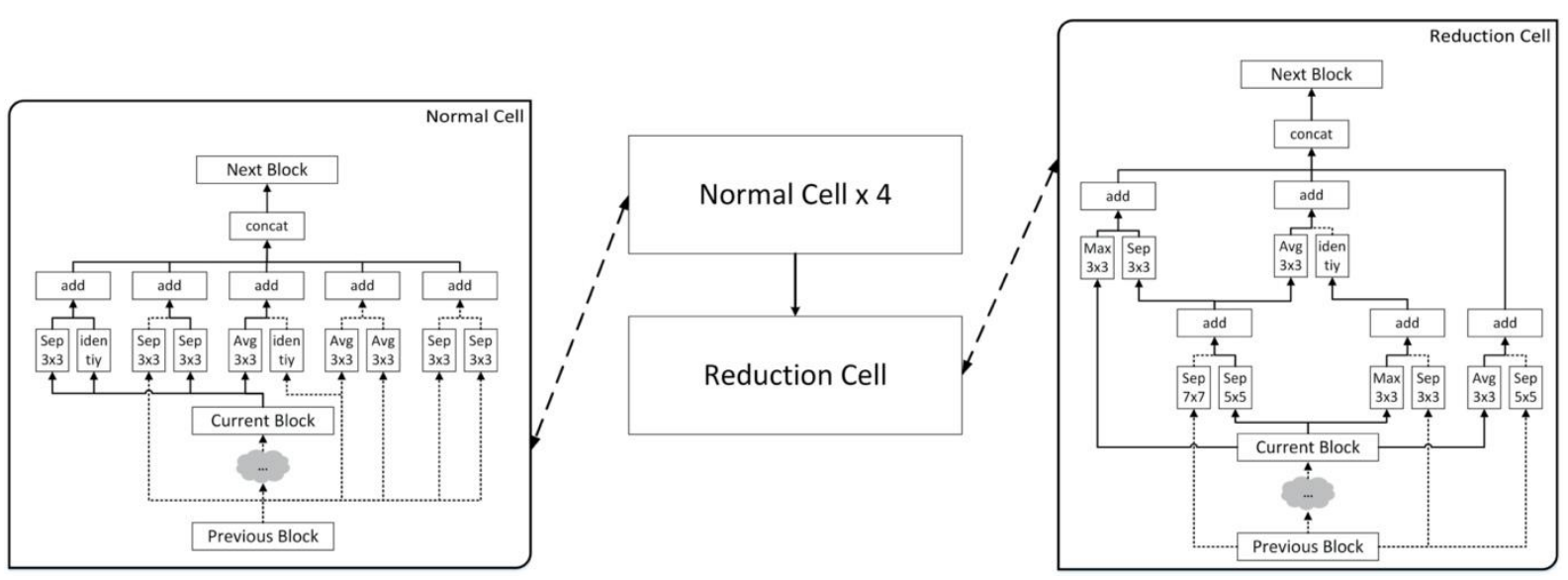

Şekil 2. NASNetMobile mimarisi [27]

\section{A.1.3. DenseNet121}

DenseNet121 mimarisinde tüm katmanların birbiri ile bağlı olması ile her katman bir önceki katmana ait özellik haritasını girdi olarak almakta ve kendi özellik haritasını bu birikime ekleyerek bir sonraki katmana iletmektedir [22]. Sürekli büyüyerek iletilen özellikler ağın uygulanabilirliğini zorlaştırmaktadır. Mimaride bu problem özellik haritalarına alt örnekleme uygulanmasıyla aşılmıştır. Bu sayede özellik haritaları limitler dâhilinde tutulmaktadır [3]-[8],[28]. 


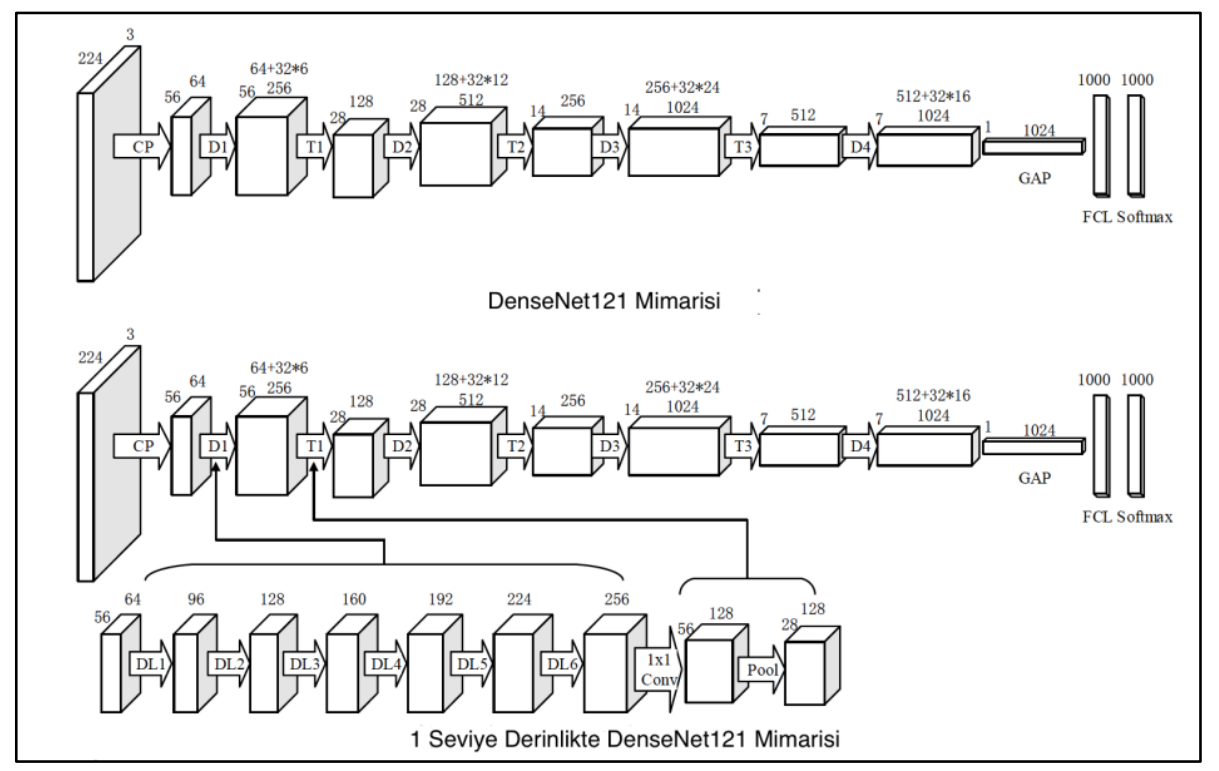

Şekil 3. DenseNet121 mimarisi [28]

\section{A.1.4. Xception}

Xception, kalan bağlantılar ve derinlemesine ayrılabilir katmanların doğrusal bir şekilde birleştirilmesi ile oluşmaktadır [29]. Derinlemesine ayrılabilir katman ise kanal bazlı evrişim ve noktasal evrişim olarak iki alt katmana ayrılmaktadır [30]. Bu mimaride görüntüler ilk aşama noktasal evrişim ikinci aşamada ise derinlemesine evrişim ile analiz edilmeye başlanmaktadır [30]. Bu mimarinin tasarlanmasındaki ana motivasyon daha çok parametre ile her türlü problemi çözmek olarak ifade edilmiştir [31].
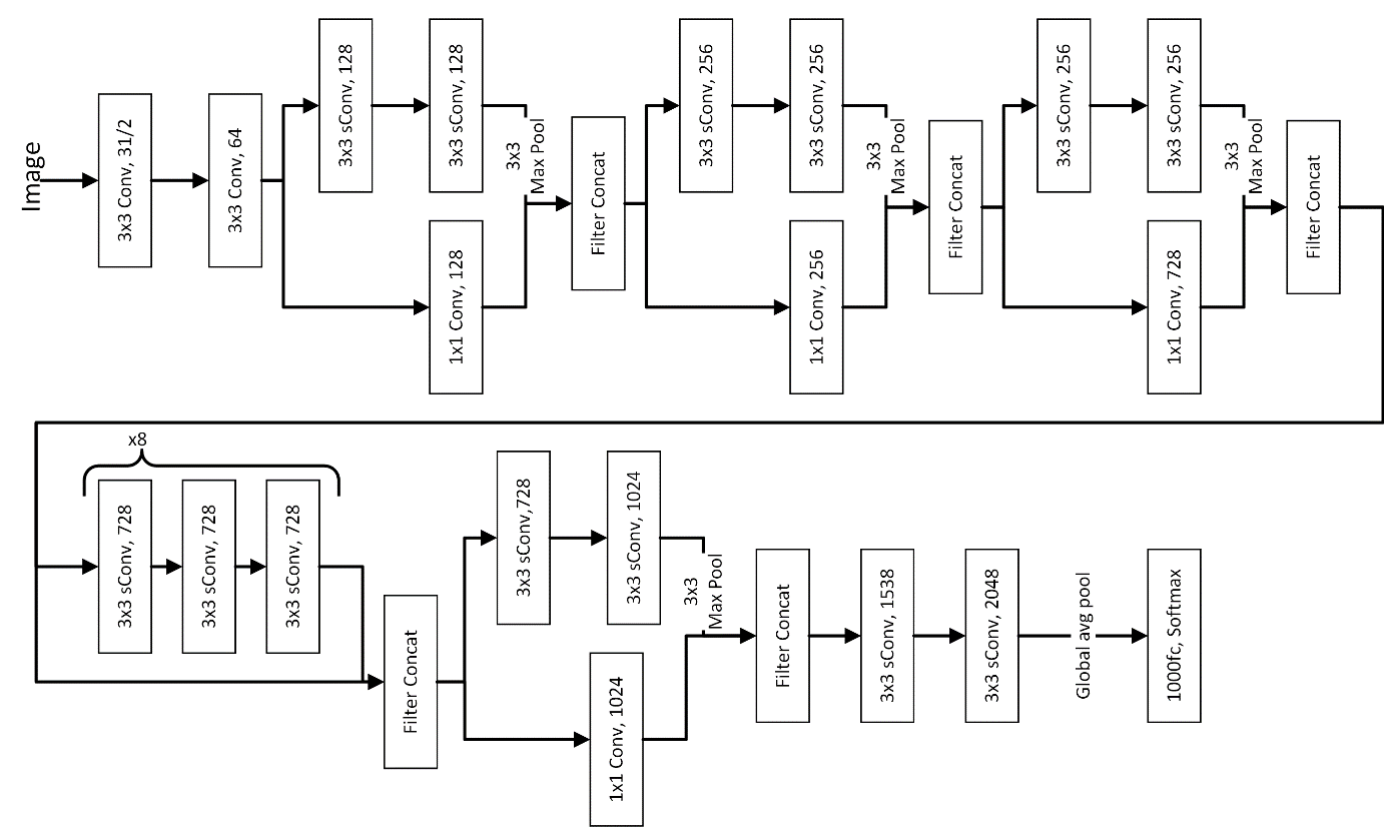

Şekil 4. Xception mimarisi [32]

\section{B. TRANSFER ÖĞRENIMI}

Makine öğrenmesi algoritmalarının etkili ve başarılı çalışabilmesi için yeterli büyükte ve kalitede veri setlerine ihtiyaç duymaktadır. Medikal alandaki sinir ağ uygulamalarında istenen düzeyde veri setinin 
olmaması sık karşılaşılan bir durumdur. $\mathrm{Bu}$ durumlarda transfer öğrenimi yaklaşımı tercih edilmektedir. Transfer öğrenimi, yeterli büyüklükte ve kalitede veriye sahip düzgün dağılım gösteren veri setlerinden çıkarılan bilgilerin aralarında ilişki bulunan algoritmalara daha iyi performans elde etme amacıyla aktarılmasıdır [33]. Transfer öğrenimi ile eğitim süresinde iyileştirme ve performansta artış elde edilmektedir [34].

\section{METOT}

Bu bölümde çalışma kapsamında izlenen yola yer verilmiştir.

\section{A. VERİ SETI}

Veri seti [35] farklı dizinlerde yer alan normal, akciğer opasitesi, viral pnömoni ve COVID-19 hastalarına ait akciğer x-ray görüntülerinin Katar ve Dakka üniversiteli uzmanlar, doktorlar tarafından derlenmesi ile oluşturulmuştur. Araştırmacıların çalışabilmesi için Kaggle üzerinden erişime açılmışıtır. Sınıflandırma etiketlerine göre yapılan incelemede 3,616 COVID-19, 6,012 opasite, 10,192 normal olmak üzere toplam 21,165 röntgen görüntüsü bulunmaktadır. Performansı artırmak ve veri setini daha dengeli hale getirmek amacıyla normal ve opasiteye ait görüntü sayısı en kıymetli veri olan COVID-19 görüntü sayısına indirilmiştir.

Tablo 1. Veri setindeki X-Ray görüntü dağılımı

\begin{tabular}{cccccc}
\hline Veri Seti & COVID-19 & $\begin{array}{c}\text { Akciğer } \\
\text { Opasitesi }\end{array}$ & Sağlıklı & $\begin{array}{c}\text { Viral } \\
\text { Pnömoni }\end{array}$ & Toplam \\
\hline Orijinal & 3,616 & 6,012 & 10,192 & 1,345 & 21,165 \\
\hline Düzenlenmiş & 3,616 & 3,616 & 3,616 & 1,345 & 11,293 \\
\hline
\end{tabular}

Aşırı öğrenmeyi önlemek ve daha değerlendirebilir metrikler elde etmek için veri seti eğitim, validasyon ve test olmak üzere üç gruba ayrılmıştır. İlk adımda \%80 eğitim \%20 test, ikinci adımda ise eğitim kümesi bu oranlarla eğitim ve validasyon olarak bölünmüştür.

\section{B. VERİ ÖNISSLEME}

Küçük veri setlerinde yaşanan aşırı öğrenme problemi karşın öğrenme aşamasında veri artırım yöntemleri tercih edilmiştir. Veri artırım yöntemleri ile daha iyi performansa odaklanan Monshi ve arkadaşlarının [7] yaptığı çalışmaya ait çıktılar bu çalışmada kullanılmıştır. Eğitim kümesindeki XRay görüntülerine; 20 derece rotasyon, 1,2 oranında yakınlaştırma, 0,3 oranında 1şık artırımı, mobil uygulamada meydana gelecek insan hatasını simüle edebilmek için genişlik ve yükseklikte 0,2 oranında öteleme uygulanmıştır.

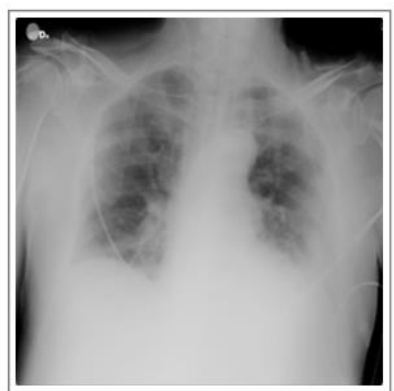

COVID-19

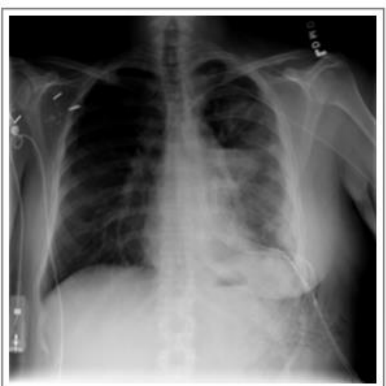

Lung Opacity

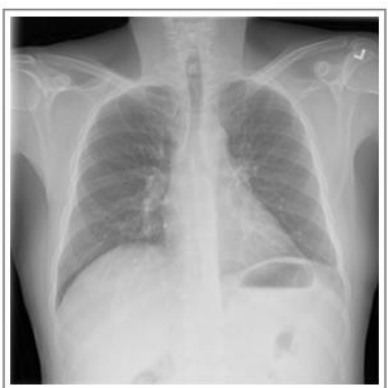

Healthy

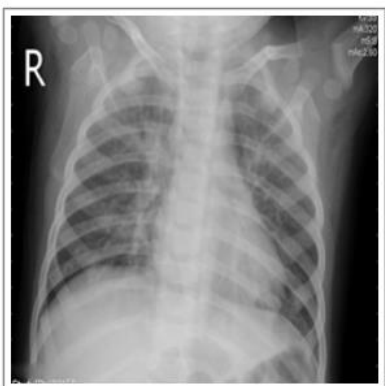

Viral Pneumonia

Sekil 5. Veri setinde bulunan sinıf etiketlerine ait X-Ray görüntüleri 


\section{UYGULAMA}

$\mathrm{Bu}$ aşamada daha dengeli hale getirilen veri seti ve artırım yöntemleri uygulanan X-Ray görüntüleri MobileNetV2, NASNetMobile, DenseNet121 ve Xception modelleri ile analiz edilmiştir. Transfer öğrenimi yaklaşımı ile modellere başlangıç ağırlıkları ImageNet veri setinden aktarılmıştır. Veri setinin küçüklüğünün negatif etkisi bu sayede azaltılmıştır.

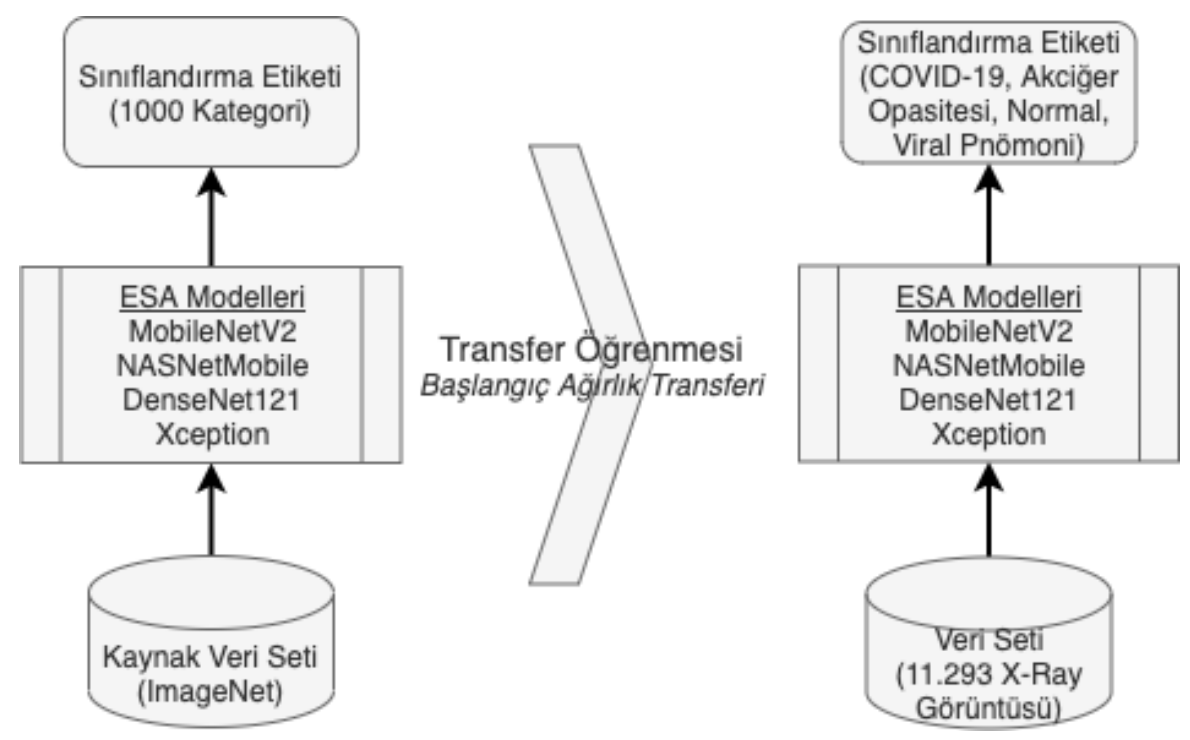

Şekil 6. Transfer öğrenmesi ile başlangıç ă̆ırlıklarının aktarılması

Modeller koşulurken kullanılan hiper parametreler; 32'lik veri paketleri, 100 döngü sayıs1, kategorik çapraz entropi yitim fonksiyonu ve adadelta optimizasyon algoritması şeklindedir. Model değerlendirme metrikleri doğruluk(accuracy) oranı olarak seçilmiş olup kesinlik(precision), duyarlılık(recall) ve özgüllük(specifity) gibi çıtılarda gözlemlenmiştir.

Sistem kaynaklarını daha verimli kullanmak adına çalışmada erken durdurma(earlystopping) mekanizması kullanılmıştır. Bu yöntem ile her iterasyonda validation loss değerindeki değişim gözlemlenmektedir. Eğer arka arkaya 15 iterasyonda herhangi değişiklik olmaz ise model sonlandırılmaktadır.

Tablo 2. Kullanılan evrişimsel sinir ağlarının genel karşılaştırılması [36],[37]

\begin{tabular}{cccccc}
\hline ESA Model & $\begin{array}{c}\text { Veri Giriş } \\
\text { Boyutu }\end{array}$ & $\begin{array}{c}\text { Boyut } \\
(M B)\end{array}$ & Ayırt Edici Özellik & $\begin{array}{c}\text { Parametre } \\
\text { Sayıs } \\
(M)\end{array}$ & $\begin{array}{c}\text { Doğruluk } \\
\text { (ImageNet } \\
\text { Top-5) }\end{array}$ \\
\hline MobileNetV2 & $224 \times 224 \times 3$ & 14 & $\begin{array}{c}\text { Tersine çevrilmiş kalan ve darboğaz } \\
\text { bloklar }\end{array}$ & 3,5 & 0,901 \\
\hline NASNetMobile & $224 \times 224 \times 3$ & 23 & Dinamik ağ mimarisi & 5,3 & 0,919 \\
\hline DenseNet121 & $224 \times 224 \times 3$ & 33 & Katmanlar arası bilgi akışı & 8 & 0,923 \\
\hline Xception & $299 \times 299 \times 3$ & 88 & $\begin{array}{c}\text { Derinlemesine evrişim ve ardından } \\
\text { noktasal evrişim }\end{array}$ & 22,8 & 0,945 \\
\hline
\end{tabular}

\section{BULGULAR VE TARTISSMA}

X-Ray görüntüleri MobileNetV2, NASNetMobile DenseNet121, Xception ESA modelleri ile COVID19, Akciğer Opasitesi, Normal ve Diğer Pnömoni etiketlerine göre ayrılmıştır. Veri seti COVID-19 görüntü sayısına göre daha dengeli hale getirilmiştir. Daha iyi sınıflandırma sonuçları elde etmek için eğitim kümesinde veri artırım yöntemleri uygulanmıştır. Veri setinin küçük olması problemini kısmen 
aşmak ve model eğitimine sıfırdan başlamak yerine transfer öğrenimi yaklaşımı başlangıç ağırlıkları ImageNet veri setinden aktarılmıştır. Elde edilen sonuçlar Tablo 3'de gösterilmiştir.

Tablo 3. ESA modellerine ait performans metrikleri

\begin{tabular}{ccccc}
\hline ESA Model & $\begin{array}{c}\text { Doğruluk } \\
\text { (Accuracy) }\end{array}$ & $\begin{array}{c}\text { Kesinlik } \\
\text { (Precision) }\end{array}$ & $\begin{array}{c}\text { Duyarlılık } \\
\text { (Recall) }\end{array}$ & $\begin{array}{c}\text { Özgüllük } \\
\text { (Specificity) }\end{array}$ \\
\hline MobileNetV2 & 0,9179 & 0,9198 & 0,9130 & 0,9978 \\
\hline NASNetMobile & 0,9110 & 0,9144 & 0,9077 & 0,9982 \\
\hline DenseNet121 & 0,9216 & 0,9253 & 0,9200 & 0,9968 \\
\hline Xception & 0,9007 & 0,9053 & 0,8942 & 0,9975 \\
\hline
\end{tabular}

Model performanslarına ait görseller aşağıda yer verilmiştir. Toplam 100 döngü(epoch) sayısı koşması planlanan algoritmalar validasyon kaybı(validation_loss) değerinde bir değişiklik olmaması ve efektif kaynak kullanımı amacıyla erken durdurma(earlystopping) mekanizması tarafindan sonlandırılmıştır. Bu nedenle grafiklerde döngü sayısında farklılıklar bulunmaktadır.

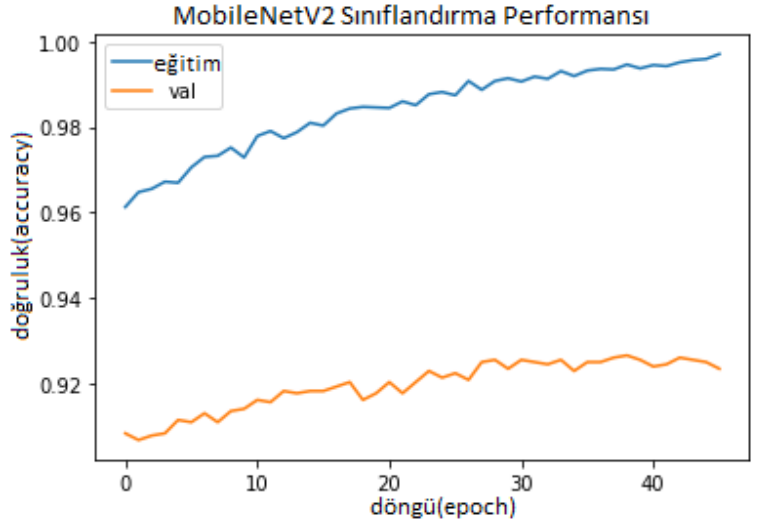

(a)

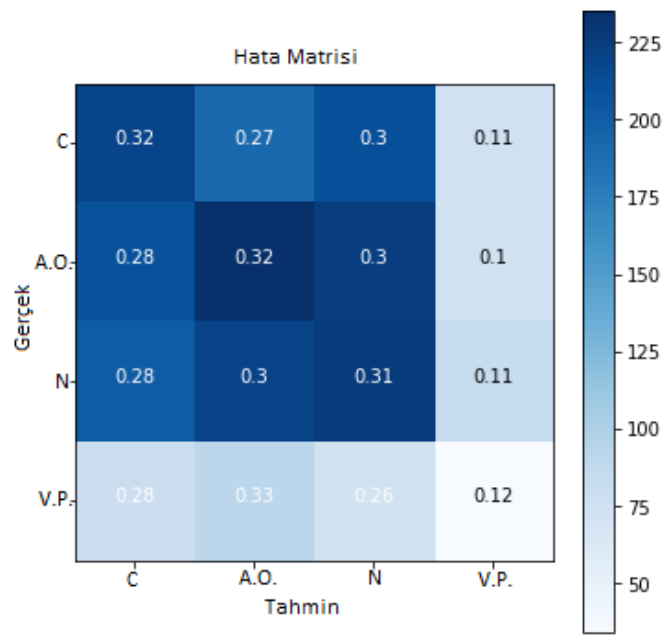

(b)

Şekil 7. (a) MobileNetV2 sınıflandırma performansı ve (b) Hata matrisi

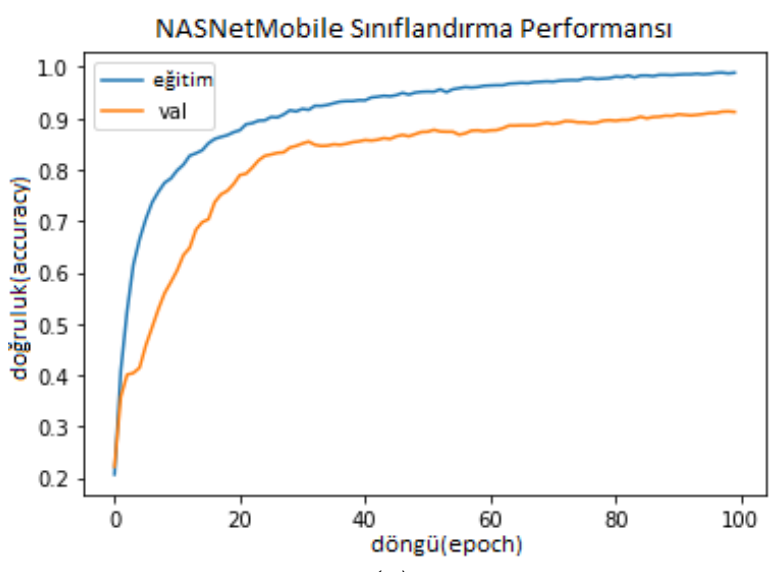

(a)

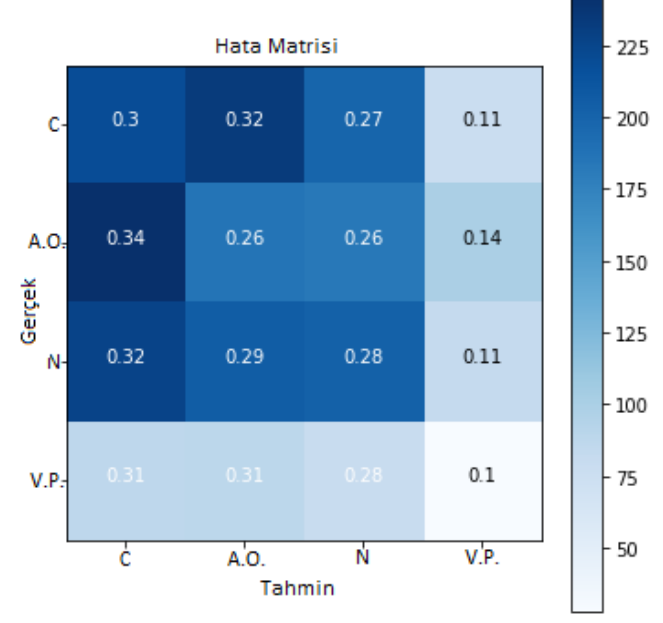

(b)

Şekil 8. (a) NASNetMobile sinıflandırma performansl ve (b) Hata matrisi 


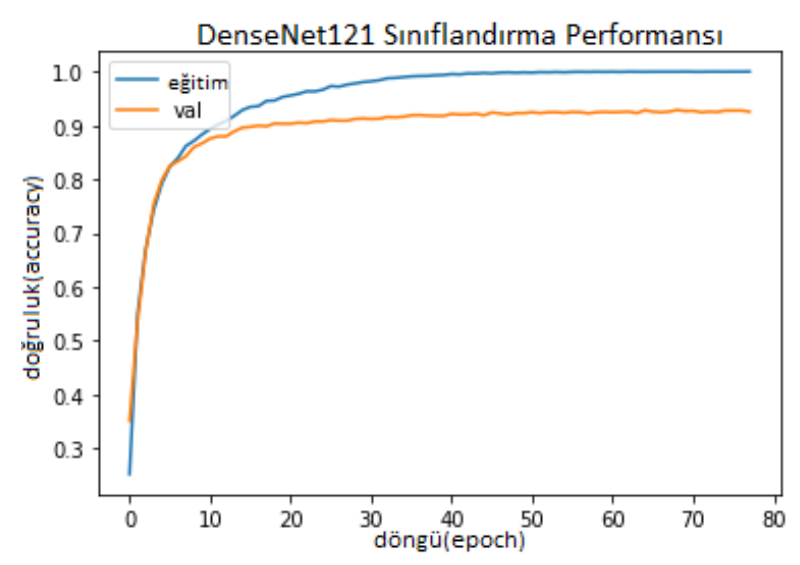

(a)

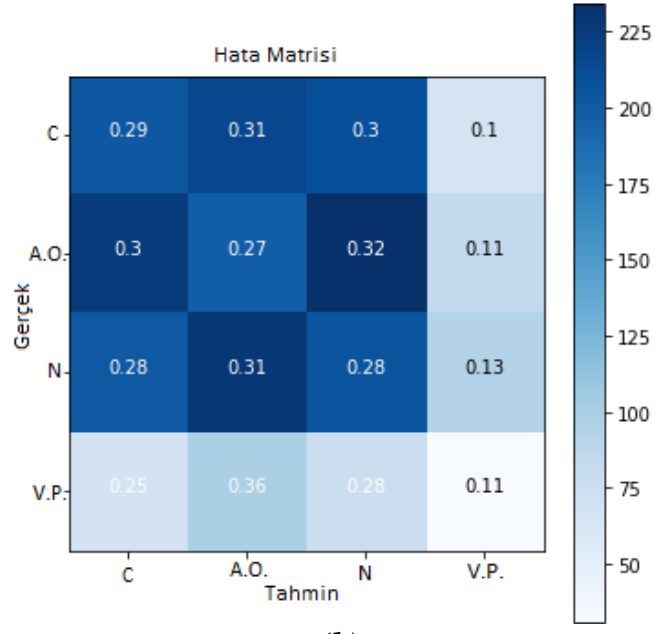

(b)

Şekil 9. (a) DenseNet121 sınıflandırma performansı ve (b) Hata matrisi

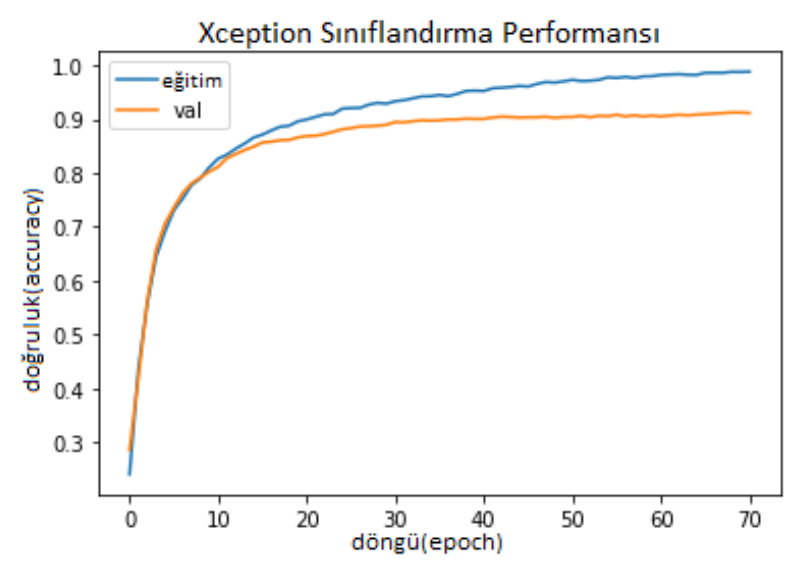

(a)

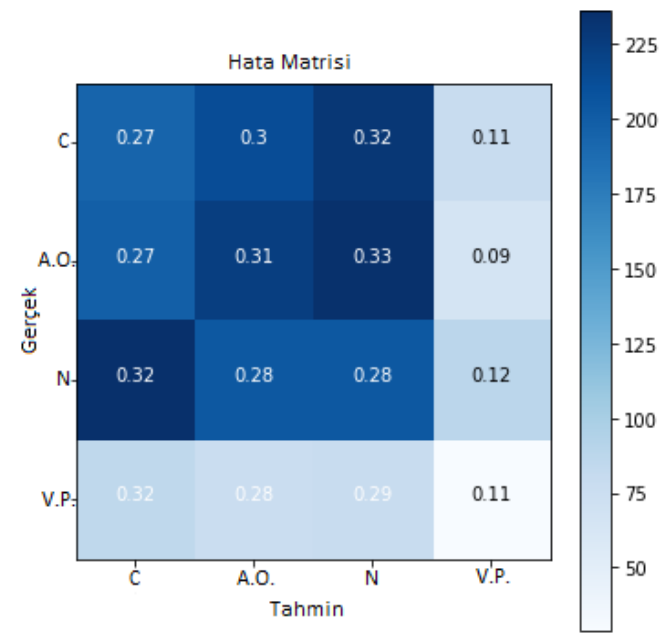

(b)

Şekil 10. (a) Xception sınıflandırma performansı ve (b) Hata matrisi

En başarılı sonuçlar DenseNet121 ve MobileNet ağlarından elde edilmiştir. Tablo 2'de belirtildiği üzere parametre sayıları ve model boyutları farklı olmasına rağmen 4 modele ait sonuçlar arasındaki performans farkı oldukça düşük çıkmıştır. En iyi sonucu veren DenseNet121 ağ 8 milyon parametre kullanarak \%92,16 doğruluk oranında sınıflandırma yaparken ikinci en iyi sonucu veren MobileNetV2 ağı 3,5 milyon parametre ile \%91,78'lik başarı oranıyla veriyi etiketlemiştir.

Hafif mimari olarak varsayılan ve mobil, IOT cihazlar gibi düşük donanımsal özelliklere sahip cihazlarda çalışan MobileNetV2 ve NASNetMobile modelleri umut vaat edici performanslar ortaya koymuştur. Çalışmanın temel amacı olan evrişimsel sinir ağları ile COVID-19 tespiti ve mobil cihazlar için uygun çözüm bulma hedeflerine, analizler sonucunda tatmin edici bulgular ile ulaşıldığı gözlemlenmiştir.

\section{V.SONUC}

Koronavirüs salgını günümüzde etkisini hala sürdürmektedir. Virüsün farklı mutasyonlarının çıkması, yeterli sayıda aşılamanın yapılamaması ve aşı dışında bir çözümün hali hazırda bulunamaması salgının uzun süre daha devam edeceğini göstermektedir. Her ülkenin salgın ile farklı yöntemlerle mücadele 
etmesine karşı, ortak izlenen yöntem olan virüs tespiti ve izolasyon hala geçerliliğini korumaktadır. $\mathrm{Bu}$ nedenle hastalık teşhisinin doğru konulması oldukça kritik öneme sahiptir. Altın standart kabul edilen ve dünyada en yaygın kullanılan PCR test yönteminin hata oranının yüksek olması bu yöntemin alternatif yöntemlerle desteklenmesi gerektiğini ortaya koymaktadır. Akciğer X-Ray görüntülerinin COVID-19'a özgü bulguları içermesi, gelişmiş ülkelerin test imkanlarına katkı sağlama ve test kitlerine erişimde problem yaşayan ülkelere bir yöntem sunma açısından umut vaat etmektedir. X-Ray görüntüleme yönteminin en büyük dezavantajı ise diğer akciğer hastalıkları ile bulguların benzerlik göstermesi ve tanının sadece uzman radyologlar tarafından konabilecek seviyede olması şeklide ifade edilmektedir.

İlgili çalışma kapsamında 11,293 akciğer X-Ray görüntüsü üzerinde akciğer opasitesi, normal, viral pnömoni ve COVID-19 etiketlerine göre sınıflandırma yapılmış ve yukarıda bahsedilen dezavantajlar DenseNet121, Xception, MobileNetV2 ve DenseNet121 evrişimsel sinir ağları ile elimine edilmeye çalışılmıştır. $\mathrm{Bu}$ ağlara ait sınıflandırma sonuçları birbirine yakın çıkmış olup en yüksek doğruluk oranları DenseNet121 ve MobileNetV2 ağlarında sırası ile \%92,16 ve \%91,79 şeklinde elde edilmiştir. Hafif ağların bu derece yüksek sonuç vermesi salgınının kontrolden çıktığı ya da doktor sayısının yetersiz kaldığı durumlar için diğer kamu görevlilerinin de tanı koyma ve izolasyon çalışmalarına, geliştirilecek mobil çözümler ile destek verebileceğine işaret etmektedir.

\section{VI. ÖNERILER VE GELECEK CALISMALAR}

Gelecek çalışmalarda daha iyi performanslar elde edebilmek için daha çok veri ile çalışmak faydalı olacaktır. Ayrıca mevcut çalışmanın diğer klinik veriler ile desteklenerek hibrit bir makine öğrenmesi yaklaşımı sunulması hastalık tespit oranını önemli ölçüde artıracaktır. Mobil cihazlara başarılı sonuçlar veren bu modellerin entegre edilmesi saha personeline önemli ölçüde katkı sağlayacaktır.

Mobil cihazlar için önerilecek sistemlerde istemciler ve sunucular arasında federe mimariler üzerine odaklanılması sistemi daha etkili hale getirecektir. Federe mimarilerde istemcilerden alınan veriler sunucularda işlenerek gerekli ağılık güncellemeleri yapılabilecek ya da başka belirtilerin de modellere eklenmesi ile kalibre edilen modeller değişen saha koşullarına göre her zaman güncel tutulabilecektir.

\section{KAYNAKLAR}

[1] J.-M. Qu, B. Cao, and R.-C. Chen, COVID-19: The Essentials of Prevention and Treatment, 1st ed., Amsterdam, Holland: Elsevier Science, 2020, ch. 1, pp 1-6.

[2] Z. Allam, Surveying the Covid-19 Pandemic and Its Implications, 1st ed., Amsterdam, Holland: Elsevier Science 2020, ch. 1, pp. 1-7.

[3] T.-M. Chen, J. Rui, Q.-P. Wang, Z.-Y. Zhao, J.-A. Cui, and L. Yin, "A mathematical model for simulating the phase-based transmissibility of a novel coronavirus," Infectious Diseases of Poverty, vol. 9, no. 1, pp. 24, 2020.

[4] World Health Organization. (2021, November 4). Naming the coronavirus disease (COVID19) and the virus that causes it [Online]. Available: https://www.who.int/emergencies/diseases/novelcoronavirus-2019/technical-guidance/naming-the-coronavirus-disease-(covid-2019)-and-the-virusthat-causes-it.

[5] J. Zheng, "Sars-cov-2: an emerging coronavirus that causes a global threat," International Journal of Biological Sciences, vol. 16, no. 10, pp. 1678, 2020. 
[6] Karthik, R. Menaka, and H. M, "Learning distinctive filters for COVID-19 detection from chest X-ray using shuffled residual CNN," Applied Soft Computing, vol. 99, pp. 106744, 2021.

[7] M. M. A. Monshi, J. Poon, V. Chung, and F. M. Monshi, "CovidXrayNet: Optimizing data augmentation and CNN hyperparameters for improved COVID-19 detection from CXR," Computers in Biology and Medicine, vol. 133, pp. 104375, 2021.

[8] World Health Orginazation. (2021, August 28). Coronavirus(COVID-19) Dashboard [Online]. Available: http://covid19.who.int.

[9] L. Wang, Z. Q. Lin, and A. Wong, "COVID-Net: a tailored deep convolutional neural network design for detection of COVID-19 cases from chest X-ray images," Scientific Reports, vol. 10, no. 1, pp. 19549, 2020.

[10] Y. Bouchareb et al., "Artificial intelligence-driven assessment of radiological images for COVID-19," Computers in Biology and Medicine, vol. 136, pp. 104665, 2021.

[11] N.-A.- Alam, M. Ahsan, M. A. Based, J. Haider, and M. Kowalski, "COVID-19 detection from chest X-ray images using feature fusion and deep learning," Sensors (Basel), vol. 21, no. 4, pp. 1480, 2021.

[12] Z. Wang et al., "Automatically discriminating and localizing COVID-19 from communityacquired pneumonia on chest X-rays," Pattern Recognition, vol. 110, pp. 107613, 2021.

[13] M. J. Horry et al., "COVID-19 detection through transfer learning using multimodal imaging data," IEEE Access, vol. 8, pp. 149808-149824, 2020.

[14] G. D. Rubin et al., "The role of chest imaging in patient management during the COVID-19 pandemic: A multinational consensus statement from the fleischner society," Radiology, vol. 296, no. 1, pp. 172-180, 2020.

[15] T. Ozturk, M. Talo, E. A. Yildirim, U. B. Baloglu, O. Yildirim, and U. Rajendra Acharya, "Automated detection of COVID-19 cases using deep neural networks with X-ray images," Computers in Biology and Medicine, vol. 121, pp. 103792, 2020.

[16] S. Karakanis and G. Leontidis, "Lightweight deep learning models for detecting COVID-19 from chest X-ray images," Computers in Biology and Medicine, vol. 130, pp. 104181, 2021.

[17] D. D. Pukale, S. G. Bhirud and V. D. Katkar, "Content-based image retrieval using deep convolution neural network," in 2017 International Conference on Computing, Communication, Control and Automation (ICCUBEA), 2017, pp. 1-5.

[18] L. L. Ankile, M. F. Heggland, and K. Krange, "Deep convolutional neural networks: A survey of the foundations, selected improvements, and some current applications," 2020, arXiv:2011.12960.

[19] D. Arora, M. Garg and M. Gupta, "Diving deep in deep convolutional neural network," in 2020 2nd International Conference on Advances in Computing, Communication Control and Networking (ICACCCN), 2020, pp. 749-751.

[20] C. Ouchicha, O. Ammor, and M. Meknassi, "CVDNet: A novel deep learning architecture for detection of coronavirus (Covid-19) from chest x-ray images," Chaos Solitons Fractals, vol. 140, pp. $110245,2020$.

[21] N. Aloysius and M. Geetha, "A review on deep convolutional neural networks," in 2017 International Conference on Communication and Signal Processing (ICCSP), 2017, pp. 0588-0592. 
[22] M. Sandler, A. Howard, M. Zhu, A. Zhmoginov, and L.-C. Chen, "MobileNetV2: Inverted residuals and linear bottlenecks," in 2018 IEEE/CVF Conference on Computer Vision and Pattern Recognition, 2018, pp. 4510-4520.

[23] E. E.-D. Hemdan, M. A. Shouman, and M. E. Karar, "COVIDX-Net: A framework of deep learning classifiers to diagnose COVID-19 in X-ray images," 2020, arXiv:2003.11055.

[24] U. Seidaliyeva, D. Akhmetov, L. Ilipbayeva, and E. T. Matson, "Real-time and accurate drone detection in a video with a static background," Sensors (Basel), vol. 20, no. 14, pp. 3856, 2020.

[25] P. Nagrath, R. Jain, A. Madan, R. Arora, P. Kataria, J. Hemanth, "SSDMNV2: A real time DNN-based face mask detection system using single shot multibox detector and MobileNetV2," Sustainable Cities and Society, vol. 66, pp. 102692, 2021.

[26] A. E. Ba Alawi and A. M. Qasem, "Lightweight CNN-based models for masked face recognition," in 2021 International Congress of Advanced Technology and Engineering (ICOTEN), 2021, pp. 1-5.

[27] Herdian, G. Putra, and Suharjito, "Classification of C2C e-commerce product images using deep learning algorithm," International Journal of Advanced Compututer Science Applications, vol. 10, no. 9, 2019, pp. 196-203.

[28] S.-H. Wang and Y.-D. Zhang, "DenseNet-201-based deep neural network with composite learning factor and precomputation for multiple sclerosis classification," ACM Transactions on Multimedia Computing, Communications, and Applications., vol. 16, no. 2s, pp. 1-19, 2020.

[29] F. Chollet, "Xception: Deep Learning with depthwise separable convolutions," in 2017 IEEE Conference on Computer Vision and Pattern Recognition (CVPR), 2017, pp. 1800-1807.

[30] Rismiyati, S. N. Endah, Khadijah and I. N. Shiddiq, "Xception architecture transfer learning for garbage classification," in 2020 4th International Conference on Informatics and Computational Sciences (ICICoS), 2020, pp. 1-4.

[31] P. Bhardwaj and A. Kaur, "A novel and efficient deep learning approach for COVID -19 detection using X-ray imaging modality," International Journal of Imaging Systems and Technology, vol. 31, no. 4, pp. 1775-1791, 2021.

[32] K. Srinivasan et al., "Performance comparison of deep CNN models for detecting driver's distraction," Computers, Materials \& Continua, vol. 68, no. 3, pp. 4109-4124, 2021.

[33] C. Tan, F. Sun, T. Kong, W. Zhang, C. Yang, and C. Liu, "A survey on deep transfer learning," 2018, arXiv:1808.01974.

[34] F. Zhuang et al., "A comprehensive survey on transfer learning," Proceedings of the IEEE, vol. 109, no. 1, pp. 43-76, 2021.

[35] Kaggle. (2021, June 6). COVID-19 Radiology Dataset [Online]. Available: https://www.kaggle.com/tawsifurrahman/covid19-radiography-database.

[36] A. Khan, A. Sohail, U. Zahoora, and A. S. Qureshi, "A survey of the recent architectures of deep convolutional neural networks," Artifical Intelligence Review, vol. 53, no. 8, pp. 5455-5516, 2020 . 
[37] Keras.io. (2021, August 29). Keras Applications [Online]. Available: https://keras.io/api/applications/. 